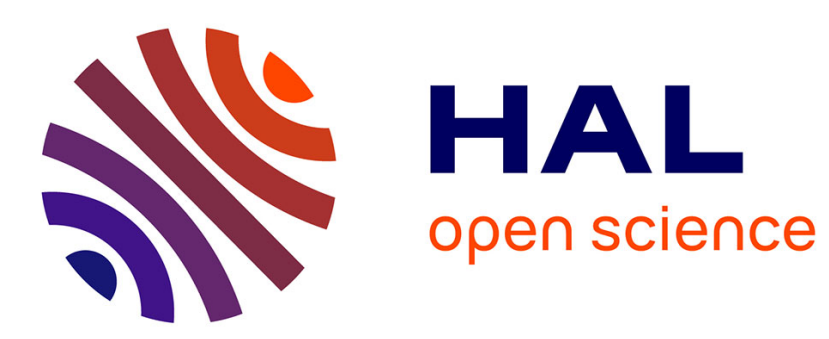

\title{
A route for the synthesis of polyaniline-based hybrid nanocomposites
}

H Kebiche, Fabienne Poncin-Epaillard, N Haddaoui, Dominique Debarnot

\section{To cite this version:}

H Kebiche, Fabienne Poncin-Epaillard, N Haddaoui, Dominique Debarnot. A route for the synthesis of polyaniline-based hybrid nanocomposites. Journal of Materials Science, 2020, 55 (14), pp.5782-5794. 10.1007/s10853-020-04406-y . hal-03015936

\section{HAL Id: hal-03015936 \\ https://hal.science/hal-03015936}

Submitted on 20 Nov 2020

HAL is a multi-disciplinary open access archive for the deposit and dissemination of scientific research documents, whether they are published or not. The documents may come from teaching and research institutions in France or abroad, or from public or private research centers.
L'archive ouverte pluridisciplinaire HAL, est destinée au dépôt et à la diffusion de documents scientifiques de niveau recherche, publiés ou non, émanant des établissements d'enseignement et de recherche français ou étrangers, des laboratoires publics ou privés. 


\title{
A route for the synthesis of polyaniline-based hybrid nanocomposites
}

\author{
H. Kebiche ${ }^{\mathrm{a}, \mathrm{b}}$, F. Poncin-Epaillard ${ }^{\mathrm{a}}$, N. Haddaoui ${ }^{\mathrm{b}}$, D. Debarnot ${ }^{\mathrm{a}, *}$ \\ ${ }^{a}$ Institut des Molécules et Matériaux du Mans, UMR 6283, CNRS, Le Mans Université, \\ Avenue Olivier Messiaen, 72085 Le Mans cedex 9, France \\ ${ }^{b}$ Laboratoire de Physico-Chimie des Hauts Polymères, Université Ferhat Abbas, 19000 Sétif, \\ Algeria \\ * Corresponding author: Dominique.Debarnot@univ-lemans.fr (D. Debarnot).
}

J. Mat. Sci. 55, 5782-5794 (2020)

\begin{abstract}
In this study, we present a new method of metal incorporation into polyaniline (PANI) nanostructures based on the use of palladium/tin colloidal solutions. This method allows controlling the size of metal particles inserted into the polymer matrix. The preparation of the PANI/Pd-Sn nanocomposites is done either with the in-situ method by addition of colloids during polymerization or with the ex-situ one by incorporation of colloids after polymerization. The results show that the in-situ addition of $\mathrm{Pd} / \mathrm{Sn}$ colloids affects mainly the morphology of the nanostructures by increasing their surface area, whereas their ex-situ incorporation affects mainly the doping level of the nanostructures by increasing the concentration of positively charged nitrogen atoms in the polymer matrix. This work is supported by analysis techniques such as X-ray photoelectron spectroscopy, UV-Vis spectrometry and scanning electron microscopy.
\end{abstract}

Keywords: polyaniline nanostructures; polymer/metal nanocomposites; palladium/tin colloidal solution. 


\section{Introduction}

Conducting polymer-metal nanocomposites are a new class of materials that combine mechanical, optical and electrical properties of conducting polymers with magnetic properties and high electrical conductivity of metallic inclusions. They offer new performance, which makes them particularly interesting for several applications such as electronics [1], sensors [2,3], photovoltaic cells [4], memory devices [5], protective coatings against corrosion [6] and supercapacitors [7]. Muraviev et al. [8] have shown that incorporating metals in conducting polymers enhances electron transfer through a direct or mediated mechanism with improved conductivity and enhanced stability. Moreover, better performance for the detection of reducing gases such as $\mathrm{NH}_{3}, \mathrm{H}_{2}$ and $\mathrm{CO}$ is proved by Torsi et al. and Inoue et al. $[9,10]$ using polypyrrole and poly-3-methylthiophene doped with copper and palladium inclusions. Polyaniline (PANI) is one of the most widely used conducting polymers due to its easy synthesis, low cost and also to its specific doping process via protonation or oxidation.

The methods reported in the literature for the preparation of polyaniline/palladium nanocomposites consist of adding a metallic salt either during the polymer synthesis or after its synthesis [11-19]. Athawale et al. [3,11] have incorporated the metallic salt $\left(\mathrm{PdCl}_{2}, 5 \mathrm{H}_{2} \mathrm{O}\right)$ during the polymerization where aniline monomer acts as stabilizer for the Pd nanoparticles, prepared by thermal reflux and $\gamma$-irradiation methods. Other methods have treated polyaniline and its derivatives in their emeraldine base [12-19] or protonated forms [19], with a Pd salt $\left(\mathrm{PdCl}_{2}\right)$ in an aqueous acidic medium. Drelinkiewicz et al. $[13,14]$, Hasik et al. $[15,19]$ and Dhaoui et al. [16] showed that in highly acidic media (1 or $2 \mathrm{M} \mathrm{HCl),} \mathrm{PANI} \mathrm{[13-16]} \mathrm{and} \mathrm{its}$ derivatives $[15,19]$ undergo a protonation with both $\mathrm{HCl}$ and $\mathrm{H}_{2} \mathrm{PdCl}_{4}$ with the incorporation of $\mathrm{Pd}(\mathrm{II})$ chloro-complexes acting as counter-ions $[17,18]$. However, in low acidic media (around $10^{-3} \mathrm{M} \mathrm{HCl}$ ), some $\mathrm{Pd}^{2+}$ ions are reduced to $\mathrm{Pd}^{0}$ with oxidation of PANI backbone which leads to a lower doping level [13]. 
In this work, the insertion of palladium nanoparticles in the PANI nanostructures is realized during (in-situ method) or after (ex-situ method) the polymerization thanks to an original method using a colloidal suspension of $\mathrm{Pd} / \mathrm{Sn}$ [20]. The PANI nanostructures are synthesized by the rapid mixing oxidation method [21]. The advantage of the colloidal suspension is the ability to control the size of Pd nanoparticles by varying their synthesis parameters. The colloidal solution consists of a suspension of nanoparticles where each nanoparticle is composed of a nucleus covered by a stabilizing layer of tin. Debarnot et al. [20] suggested that the nucleus is formed by a mixture of palladium and tin.

The objectives of this study are to describe the chemical and the morphological structures of the nanocomposites elaborated by the two methods (in-situ or ex-situ one), and also to determine the mechanisms of interaction between the colloidal particles and the PANI nanostructures.

\section{Experimental}

\subsection{Materials}

Aniline monomer (Aldrich, 99.5\%) was distilled under vacuum prior to use, ammonium persulfate (APS) $\left(\left(\mathrm{NH}_{4}\right)_{2} \mathrm{~S}_{2} \mathrm{O}_{8}\right.$ Sigma-Aldrich, 98\%) and all other reagents purchased from Aldrich were used as received without further purification.

\subsection{Elaboration and deposition of polyaniline nanostructures}

The polyaniline nanostructures have been synthesized by the rapid mixing polymerization method.

In a typical synthesis, $0.46 \mathrm{~g}\left(0.1 \mathrm{~mol} . \mathrm{L}^{-1}\right)$ of aniline was dissolved in $50 \mathrm{~mL}$ of $1 \mathrm{~mol} . \mathrm{L}^{-1}$ $\mathrm{HCl}$ aqueous solutions. $1.16 \mathrm{~g}$ of $\mathrm{APS}$, corresponding to an oxidant-to-monomer mole ratio 
equals to 1 , was also dissolved in $50 \mathrm{~mL}$ of 1 mol. $\mathrm{L}^{-1}$ aqueous hydrochloric acid solution. These two solutions were then kept at a temperature of $4-5^{\circ} \mathrm{C}$ for 30 minutes.

The substrates $\left(\mathrm{Si} / \mathrm{SiO}_{2}\right.$ wafer or glass) were introduced in the monomer solution. APS solution was then added rapidly, under a vigorous dynamic stirring. After about 30 minutes of reaction, uniform thin layers of PANI nanostructures were obtained on the surface of the substrates. They were then rinsed with distilled water, dried under air flow and immerged in 1 mol. $\mathrm{L}^{-1} \mathrm{HCl}$ solution for 10 minutes then dried under air flow at room temperature.

\subsection{Preparation of $\mathrm{Pd} / \mathrm{Sn}$ colloidal solutions}

The colloidal solutions were prepared by mixing two aqueous hydrochlorhydric solutions of $\mathrm{PdCl}_{2}$ and $\mathrm{SnCl}_{2}\left(1.06\right.$ g.L. $\mathrm{PdCl}_{2} ; 4.25$ g.L $\left.\mathrm{L}^{-1} \mathrm{SnCl}_{2}, 2 \mathrm{H}_{2} \mathrm{O} ; 0.34 \mathrm{~L} . \mathrm{L}^{-1} \mathrm{HCl} 37 \%\right)$ at a given temperature $T$. In this work, two temperatures $T$ have been studied: $25^{\circ} \mathrm{C}$ and $40^{\circ} \mathrm{C}$. In this step, the formed nucleus of the colloidal particle grew during a time $t_{g}(1 \mathrm{~h}$ or $6 \mathrm{~h})$ at each temperature $T$. When the reaction time is higher than $t_{g}$, the nucleus growth was stopped by the addition of an excess of a $\mathrm{SnCl}_{2}$ solution $\left(575\right.$ g.L $\mathrm{L}^{-1} \mathrm{SnCl}_{2}, 2 \mathrm{H}_{2} \mathrm{O} ; 0.5 \mathrm{~L} . \mathrm{L}^{-1} \mathrm{HCl} 37 \%$ ), which stabilizes the solution. Therefore, the colloidal solution consists of a suspension of nanoparticles where each nanoparticle is composed of the nucleus covered by a stabilizing layer of tin. The colloidal solutions were freshly prepared and stored in the dark, at around $4^{\circ} \mathrm{C}$ and under nitrogen atmosphere.

The colloidal solution prepared at $t_{g}=1 \mathrm{~h}$ and $T=25^{\circ} \mathrm{C}$ is so-called solution A; the one prepared at $t_{g}=6 \mathrm{~h}$ and $T=25^{\circ} \mathrm{C}$ is so-called solution B and finally the solution elaborated at $t_{g}=1 \mathrm{~h}$ and $T=40^{\circ} \mathrm{C}$ is so-called solution C. The solution prepared at $t_{g}=6 \mathrm{~h}$ and $T=40^{\circ} \mathrm{C}$ is not studied here due to its low stability leading to a rapid precipitation of the colloids.

\subsection{Elaboration of polyaniline/Pd-Sn nanocomposites}


The nanocomposites have been elaborated by two methods. One of them, called the in-situ method, consists of adding $9 \mathrm{~mL}$ of the colloidal solution into the polymerization reaction during polyaniline synthesis at room temperature. Concerning the ex-situ method, after ANI polymerization, the thin layers of PANI nanostructures were introduced into the colloidal solution for 10 minutes at room temperature.

Whatever the method, the next step consisted of rinsing the films with deionised water and drying them under air flow. Then, the films were immersed into $1 \mathrm{M} \mathrm{HCl}$ aqueous solution during $5 \mathrm{~min}$ in order to remove the tin layer. The films were again rinsed with deionised water and dried under air flow.

\subsection{Characterization of PANI/Pd-Sn nanocomposites}

The layers have been analyzed by different characterization techniques like UltravioletVisible (UV-vis), X-ray photoelectron (XPS) spectroscopies and scanning electron microscopy (SEM) in order to characterize the chemical and morphological structure of the layer.

UV-vis spectra of thin films, deposited onto glass substrates, have been recorded using Cary 100 spectrophotometer (Varian). Windows-based Cary software was used for data acquisition and analysis.

The chemical nature of the layers deposited onto $\mathrm{Si} / \mathrm{SiO}_{2}$ wafers was also determined by XPS using ESCA LHS 12 instrument (Leybold) at the Laboratoire de Physique des Couches Minces (Institut des Matériaux de Nantes, France). The photoemission was excited by a monochromatic $\mathrm{Mg} \mathrm{K \alpha}$ beam at $1253.6 \mathrm{eV}$. The spectra were taken with the electron emission angle at $90^{\circ}$ relative to the sample surface, yielding a maximum sampling depth around $10 \mathrm{~nm}$ due to the mean free path of the electrons. Calibration was conducted on the $\mathrm{C}$ 1s peak of the $\mathrm{C}-\mathrm{C}$ and $\mathrm{C}-\mathrm{H}$ bonds at $285 \mathrm{eV}$. The binding energy error was $0.1 \mathrm{eV}$. The 
curve fitting was performed using CasaXPS software (Casa Software Ltd.). The peak shape was chosen with Gaussian (70\%) / Lorentzian (30\%) curve fitting. The elemental quantification accuracy was $5 \%$.

The morphology of the nanocomposites was obtained using a XL30-FEG (field emission gun) SEM microscope (Philips).

\section{Results and Discussion}

\subsection{Study of Pd/Sn colloidal solutions}

Figure 1 shows UV-Vis spectra of $\mathrm{PdCl}_{2}$ and $\mathrm{SnCl}_{2}$ solutions prepared in strongly $\mathrm{HCl}$ acidic medium, before (Figure $1 \mathrm{a}$ and $1 \mathrm{~b}$ respectively) and after (Figure 1c) their mixing to prepare the colloidal solution.

The $\mathrm{PdCl}_{2}$ solution shows an absorption maximum at $475 \mathrm{~nm}$, a wide band at about 220$290 \mathrm{~nm}$ and a last one at $300-310 \mathrm{~nm}$. The two first bands are attributed to $\mathrm{Pd}^{2+}$ ions whereas the last one is assigned to different ionic palladium complexes that may co-exist in the $\mathrm{PdCl}_{2}$ acidic solution [3,13,15,22-24]. In particular, Hasik et al. $[13,15]$ have studied the effect of $\mathrm{HCl}$ concentration on the formation of ionic palladium complexes in $\mathrm{PdCl}_{2} / \mathrm{HCl}$ solutions. They have shown that in a strong acid medium (1-2 $\mathrm{M}$ ), the concentration of anionic complexes $\left(\left[\mathrm{PdCl}_{4}\right]^{2-},\left[\mathrm{PdCl}_{3}\left(\mathrm{H}_{2} \mathrm{O}\right)\right]^{-}\right)$increases, but in a weakly acid environment $\left(\sim 10^{-3} \mathrm{M}\right)$, neutral and positively charged complexes $\left(\left[\mathrm{PdCl}_{2}\left(\mathrm{H}_{2} \mathrm{O}\right)_{2}\right]\right.$ and $\left.\left[\mathrm{PdCl}\left(\mathrm{H}_{2} \mathrm{O}\right)_{3}\right]^{+}\right)$predominate.

The $\mathrm{SnCl}_{2} / \mathrm{HCl}$ solution presents a single absorption band centered at a wavelength lower than $280 \mathrm{~nm}$ that corresponds to $\mathrm{Sn}^{2+}$ ions. 


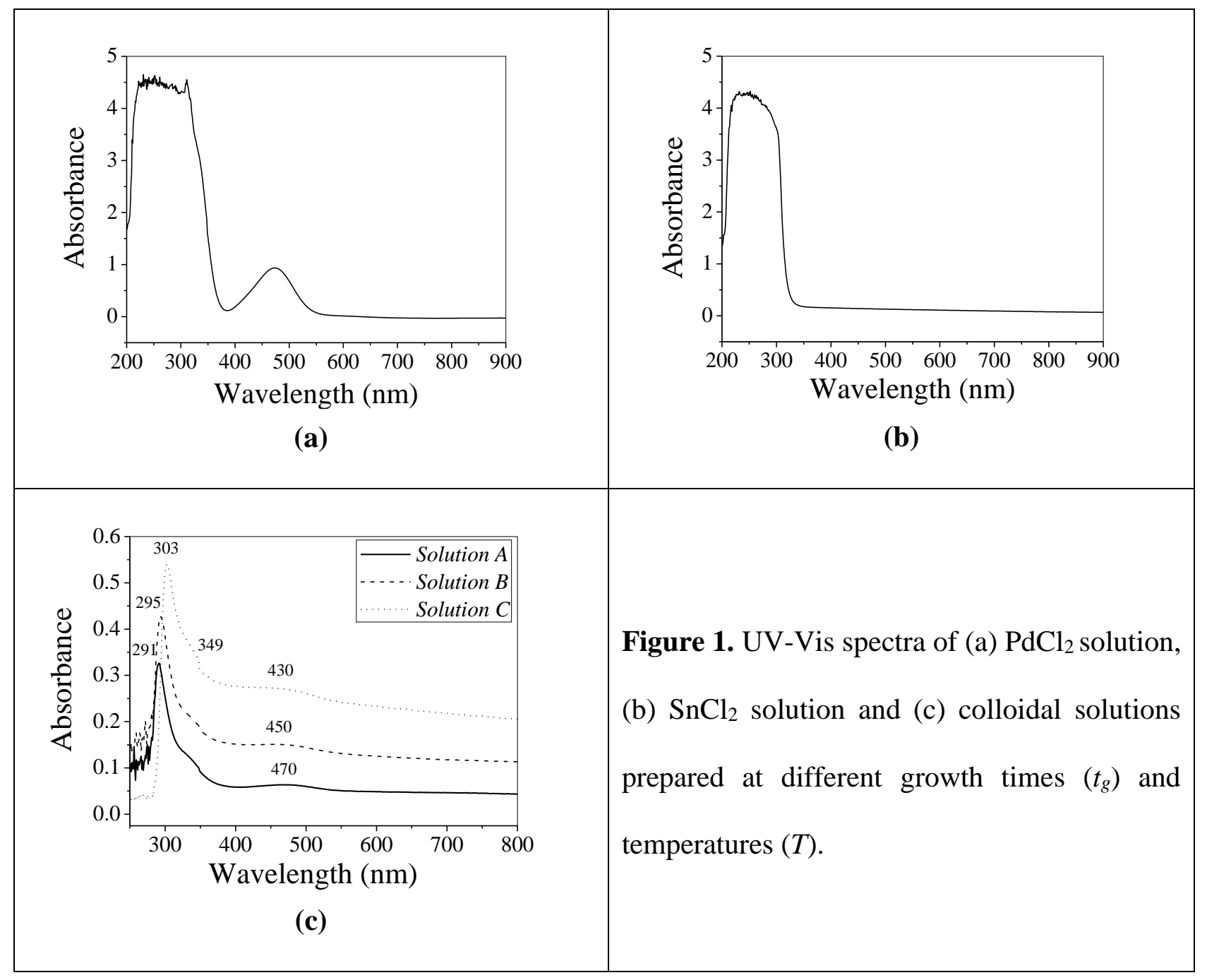

For the preparation of colloids, the above two solutions are mixed during the chosen time $t_{g}$ at the temperature $T$.

The UV-visible analysis of the mixed solution (Figure 1c) shows that the band at $475 \mathrm{~nm}$ decreases in intensity and is shifted to lower wavelengths whereas the broad band at $220-290$ $\mathrm{nm}$ disappears. This result indicates the reduction of palladium ions $\left(\mathrm{Pd}^{2+}\right)$ to their metallic state $\left(\mathrm{Pd}^{0}\right)\left(\mathrm{E}^{0}\left(\mathrm{Pd}^{2+} / \mathrm{Pd}\right)=0.99 \mathrm{~V}\right)$ by $\mathrm{Sn}^{2+}$ ions $\left(\mathrm{E}^{0}\left(\mathrm{Sn}^{4+} / \mathrm{Sn}^{2+}\right)=0.14 \mathrm{~V}\right)$, leading to the formation of the nucleus of the nanoparticle according to the following reaction [20]:

$$
\mathrm{Pd}^{2+}+\mathrm{Sn}^{2+} \rightarrow \mathrm{Pd}^{0}+\mathrm{Sn}^{4+}
$$

This is confirmed by the appearance of shoulders at $330-355 \mathrm{~nm}$ attributed to $\mathrm{Pd}^{0}$ absorption [11,25]. The intensity of these bands increases with $t_{g}$ and $T$ indicating the rise of the nucleus 
size with that of $t_{g}$ and $T$. Indeed, by referring to the results obtained by Froment et al. [16], the average nucleus size when the mixed solution is prepared at $25^{\circ} \mathrm{C}\left(t_{g}=1 \mathrm{~h}\right)$ is evaluated at around $1 \mathrm{~nm}$, and that obtained when the mixed solution is fabricated at $40^{\circ} \mathrm{C}\left(t_{g}=1 \mathrm{~h}\right)$ is evaluated at around $3 \mathrm{~nm}$. Furthermore, Gaikwad et al. [25] also observed broad shoulders at 370-390 nm assigned to $\mathrm{Pd}^{0}$ where the mean size of palladium nanoparticles has been estimated at $3 \mathrm{~nm}$. In the case of Athawale et al. [11] who studied the elaboration of palladium nanoparticles by thermal reflux and $\gamma$-irradiation methods, metallic palladium shows UV-Vis absorption bands at about 320 and $317 \mathrm{~nm}$, with an average size of about 24 $\mathrm{nm}$ and $28 \mathrm{~nm}$ respectively.

Finally, Figure 1c shows the presence of absorption bands situated between 291 and $303 \mathrm{~nm}$. They indicate the presence of ionic complexes of Pd and Sn in the colloids.

\subsection{Study of PANI / Pd-Sn nanocomposites elaborated by the in-situ method}

\section{Chemical structure of the nanocomposites}

The XPS wide scan (not shown here) of HCl-doped PANI nanostructures shows the presence of carbon, nitrogen and chlorine, whereas the nanocomposites present in addition, palladium and tin. The elemental composition of PANI nanostructures and PANI/Pd-Sn nanocomposites prepared with the different colloidal solutions is presented in Table 1.

According to Table 1, the amount of $\mathrm{Pd}$ and $\mathrm{Sn}$ in the nanocomposites is low, independently of the synthesis conditions of colloidal solutions. It may be due to the addition of a low amount of colloidal solution in the reaction medium. 
Table 1. Elemental composition of PANI nanostructures and PANI/Pd-Sn nanocomposites (XPS data).

\begin{tabular}{|c|c|c|c|c|c|}
\hline $\begin{array}{c}\text { Element } \\
\text { (relative \%) }\end{array}$ & C & N & Cl & Pd & Sn \\
\hline PANI nanostructure & $84.1 \pm 4.2$ & $11.2 \pm 0.6$ & $4.7 \pm 0.2$ & - & - \\
\hline $\begin{array}{c}\text { PANI/Pd-Sn nanocomposite } \\
\text { Solution A }\end{array}$ & $82.9 \pm 4.1$ & $12.1 \pm 0.6$ & $4.7 \pm 0.2$ & $0.20 \pm 0.01$ & $0.10 \pm 0.01$ \\
\hline $\begin{array}{c}\text { PANI/Pd-Sn nanocomposite } \\
\text { Solution B }\end{array}$ & $83.8 \pm 4.2$ & $12.1 \pm 0.6$ & $3.9 \pm 0.2$ & $0.10 \pm 0.01$ & $0.10 \pm 0.01$ \\
\hline $\begin{array}{c}\text { PANI/Pd-Sn nanocomposite } \\
\text { Solution C }\end{array}$ & $85.2 \pm 4.3$ & $9.9 \pm 0.5$ & $4.6 \pm 0.2$ & $0.30 \pm 0.01$ & 0 \\
\hline
\end{tabular}

Figure 2 presents the $\mathrm{N}$ 1s XPS core-level spectra of PANI nanostructures and nanocomposites. The $\mathrm{N}$ 1s spectra can be decomposed into four components at $397.9 \mathrm{eV}$ attributed to imines (-N=), at $399.2 \mathrm{eV}$ assigned to amines (-NH-), at $400.7 \mathrm{eV}$ and $402.3 \mathrm{eV}$ due to positively charged nitrogen $(-\stackrel{+*}{\mathrm{~N} H}-$ and $-\stackrel{+}{\mathrm{N}} \mathrm{H}=)$. Most authors $[26,27]$ attribute the component at $400.7 \mathrm{eV}$ to oxidized amine $(-\stackrel{+*}{\mathrm{NH}}-)$ and the other one at $402.3 \mathrm{eV}$ to protonated imine $(-\stackrel{+}{\mathrm{N}} \mathrm{H}=)$ since the doping occurs either through the protonation of imines or the oxidation of amines. The positively charged nitrogen allows then evaluating the doping level of the polymer.

Table 2 summarizes the binding energy and percentage of each $\mathrm{N} 1 \mathrm{~s}$ component determined from Figure 2. 


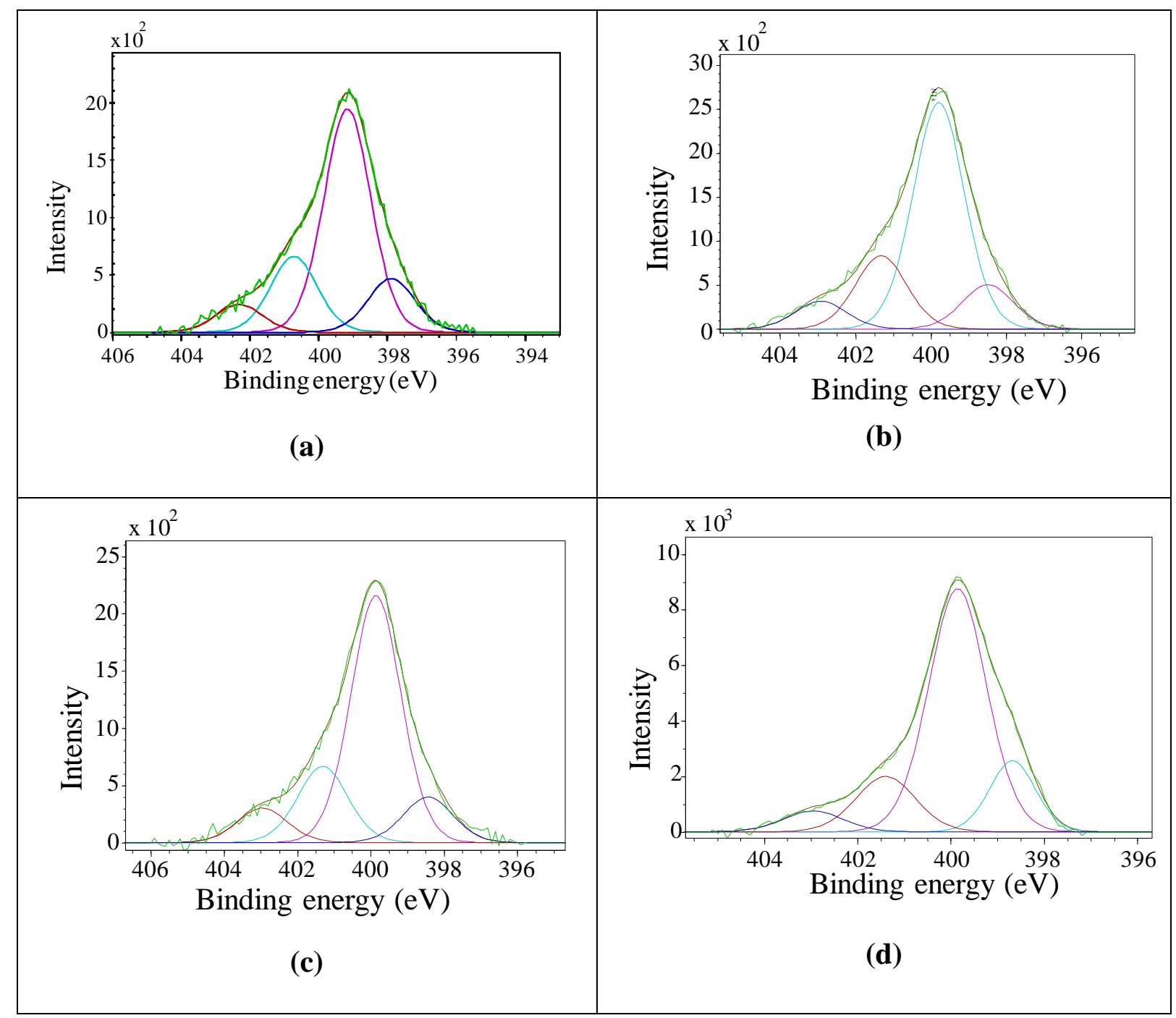

Figure 2. N 1s XPS core-level spectra of (a) PANI nanostructures, (b, c, d) PANI/Pd-Sn nanocomposites elaborated with colloids prepared at (b) $t_{g}=1 \mathrm{~h}, T=25^{\circ} \mathrm{C}$, or (c) $t_{g}=6 \mathrm{~h}, T=$ $25^{\circ} \mathrm{C}$, or $(\mathrm{d}) t_{g}=1 \mathrm{~h}, T=40^{\circ} \mathrm{C}$.

Table 2. Binding energy and percentage of each N 1s component of PANI nanostructures and PANI/Pd-Sn nanocomposites (XPS data).

\begin{tabular}{|c|c|c|c|c|c|c|c|c|c|c|}
\hline & \multicolumn{2}{|c|}{$-\mathrm{N}=$} & \multicolumn{2}{|c|}{-NH- } & \multicolumn{5}{|c|}{$-\stackrel{+*}{N^{+*}}-$ and $-\stackrel{+}{N H}^{+}=$} & \multirow{2}{*}{$\begin{array}{c}- \\
\mathrm{NH}- \\
/-\mathrm{N}=\end{array}$} \\
\hline & $\begin{array}{c}\text { Position } \\
(\mathrm{eV})\end{array}$ & $\%$ & $\begin{array}{l}\text { Position } \\
(\mathrm{eV})\end{array}$ & $\%$ & $\begin{array}{l}\text { Position } \\
(\mathrm{eV})\end{array}$ & $\%$ & $\begin{array}{l}\text { Position } \\
(\mathrm{eV})\end{array}$ & $\%$ & $\begin{array}{l}\text { Total } \\
(\%)\end{array}$ & \\
\hline $\begin{array}{c}\text { PANI } \\
\text { nanostructure }\end{array}$ & 397.9 & 14.2 & 399.15 & 58.65 & 400.7 & 20 & 402.3 & 7.2 & 27.2 & 4.1 \\
\hline
\end{tabular}




\begin{tabular}{|c|c|c|c|c|c|c|c|c|c|c|}
\hline $\begin{array}{c}\text { PANI/Pd-Sn } \\
\text { nanocomposite } \\
\text { Solution A }\end{array}$ & 398.5 & 11.9 & 399.8 & 61 & 401.3 & 19.6 & 402.9 & 7.5 & 27.1 & 5.1 \\
\hline $\begin{array}{c}\text { PANI/Pd-Sn } \\
\text { nanocomposite } \\
\text { Solution B }\end{array}$ & 398.4 & 11.4 & 399.85 & 61.15 & 401.3 & 18.95 & 402.95 & 8.5 & 27.45 & 5.35 \\
\hline $\begin{array}{c}\text { PANI/Pd-Sn } \\
\text { nanocomposite } \\
\text { Solution C }\end{array}$ & 398.7 & 14.85 & 399.85 & 64.15 & 401.4 & 15.2 & 402.95 & 5.8 & 21 & 4.3 \\
\hline
\end{tabular}

After addition of Pd-Sn colloids in PANI nanostructures, no significant differences appear in the chemical structure of the composites. The doping level remains constant except for the composite synthesized with colloidal solution $\mathrm{C}$ where the amount of positively charged nitrogen decreases slightly. Moreover, for composites prepared from colloidal solutions A and $\mathrm{B}$, the imine proportion decreases whereas that of amine increases. It means that PANI goes to its reduced form after addition of colloids. This result shows the redox reaction of the imines of the polymer $\left(\mathrm{E}^{0}(-\mathrm{N}=/-\mathrm{NH}-=0.7-0.75 \mathrm{~V}[28])\right.$ with $\mathrm{Sn}^{2+}$ ions $\left(\mathrm{E}^{0}\left(\mathrm{Sn}^{4+} / \mathrm{Sn}^{2+}\right)=\right.$ $0.14 \mathrm{~V}$ ). This reaction is not possible for nanocomposites prepared at $T=40^{\circ} \mathrm{C}$ since no tin is detected (Table 1).

\section{Morphological structure of the nanocomposites}

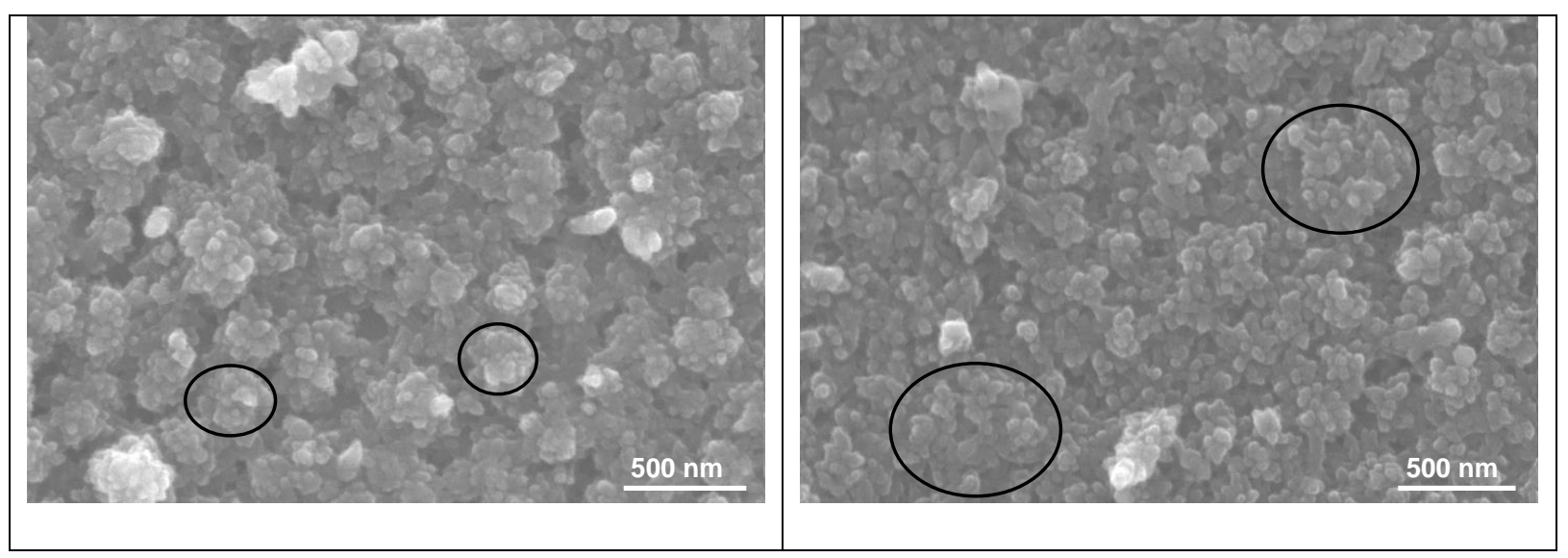




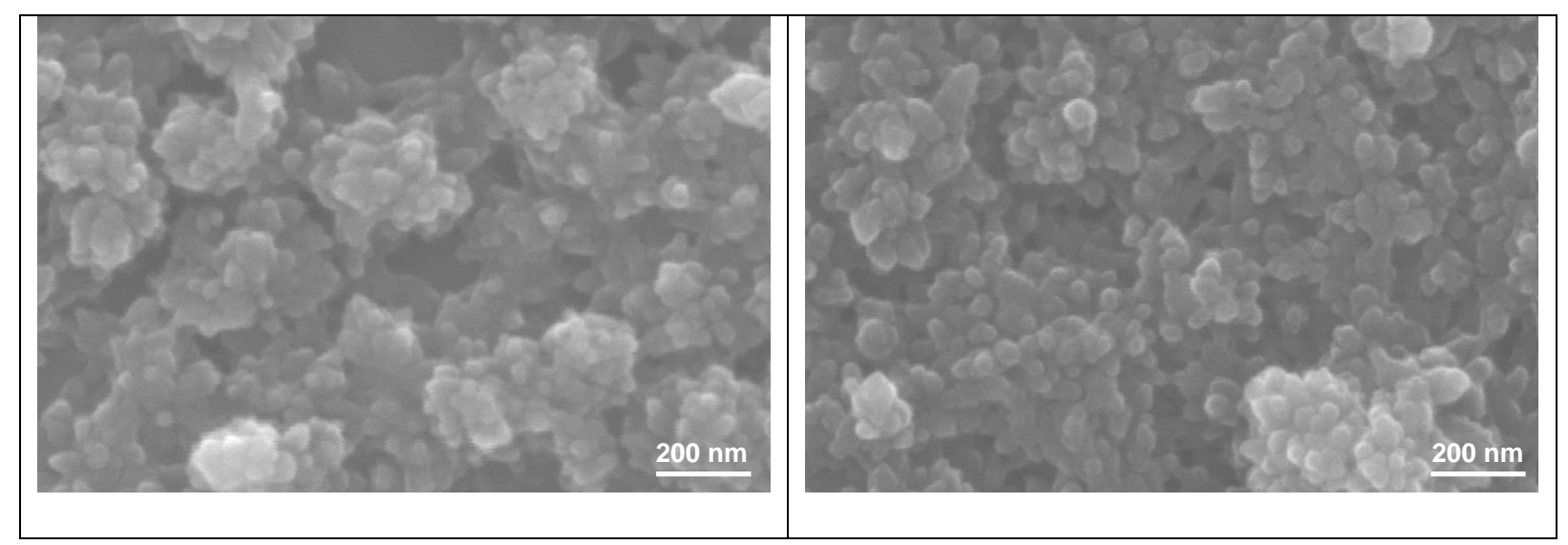

(a)

(b)

Figure 3. SEM micrographs of (a) PANI nanostructures and (b) in-situ PANI/Pd-Sn nanocomposites.

As reported in our previous work [21], the morphology of the PANI nanostructures obtained by the rapid mixing oxidation method (Figure 3a) corresponds to a cauliflower-like structure with two levels of topography: nanoparticles with dimensions of about 200-300 nm, and on these particles, a divided surface. As seen on figure $3 \mathrm{~b}$, the morphology of PANI nanostructures seems to be affected by the in-situ addition of colloids. The diameter of the nanostructures is more important and can reach 500 to $600 \mathrm{~nm}$. The surface seems to be more divided leading then to an important developed surface area.

\subsection{Study of PANI / Pd-Sn nanocomposites elaborated by the ex-situ method}

\section{Chemical structure of the nanocomposites}

Figure 4 presents the elemental composition of PANI nanostructures and PANI/Pd-Sn nanocomposites elaborated by the ex-situ method with the different colloidal solutions and determined by XPS. 


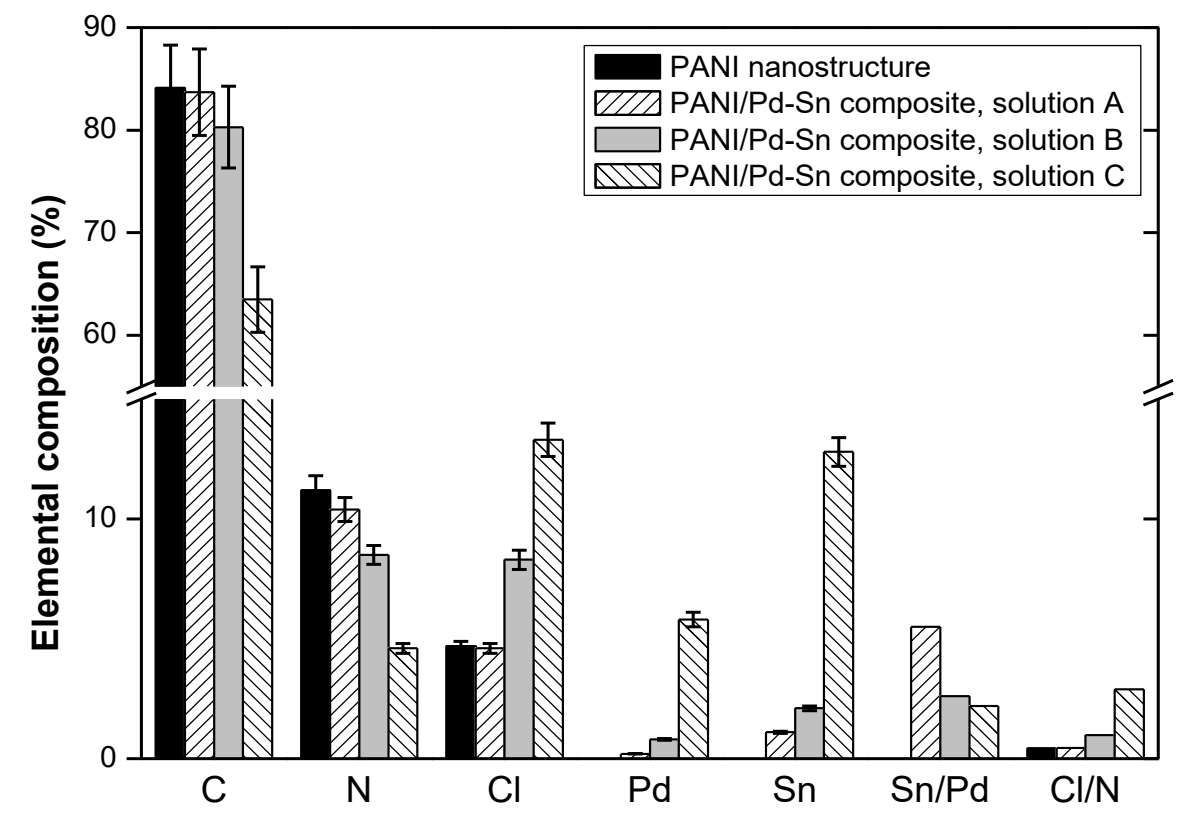

Figure 4. Elemental composition of PANI nanostructures and PANI/Pd-Sn nanocomposites (XPS data).

When the composites are elaborated with colloidal solutions $\mathrm{B}$ or $\mathrm{C}$, the amount of $\mathrm{Cl}, \mathrm{Pd}$ and $\mathrm{Sn}$ is high compared to composites elaborated by the in-situ method. Therefore, this method allows the incorporation of a higher amount of metallic particles. These results show the presence of both $\mathrm{Pd}$ and $\mathrm{Sn}$ in the nucleus of the colloidal particle. However, the proportion of $\mathrm{Sn}$ in the nucleus, compared to $\mathrm{Pd}$, decreases when the nucleus size increases as shown by the $\mathrm{Sn} / \mathrm{Pd}$ ratio. Furthermore, the concentration of adsorbed $\mathrm{Pd}$ and $\mathrm{Sn}$ is higher when $t_{g}$ and $T$ are high in accordance with bigger average nucleus size observed with the rise of $t_{g}$ and $T($ see $\S 3.1)$.

Figure 4 shows also the increase of $\mathrm{Cl} / \mathrm{N}$ ratio in the nanocomposites with the raise of the growth time $\left(t_{g}\right)$ or the temperature $(T)$ chosen for the colloids' synthesis. This increase is due, in part, to anionic complexes $\left(\left[\mathrm{PdCl}_{4}\right]^{2-},\left[\mathrm{PdCl}_{3}\left(\mathrm{H}_{2} \mathrm{O}\right)\right]^{-}\right)$that predominate in strong acidic medium (1 M). 
Figure 5 shows the N 1s XPS core-level spectra of PANI nanocomposites synthesized by the ex-situ method. Table 3 gives the binding energy and percentage of each $\mathrm{N} 1$ s component determined from Figure 5.

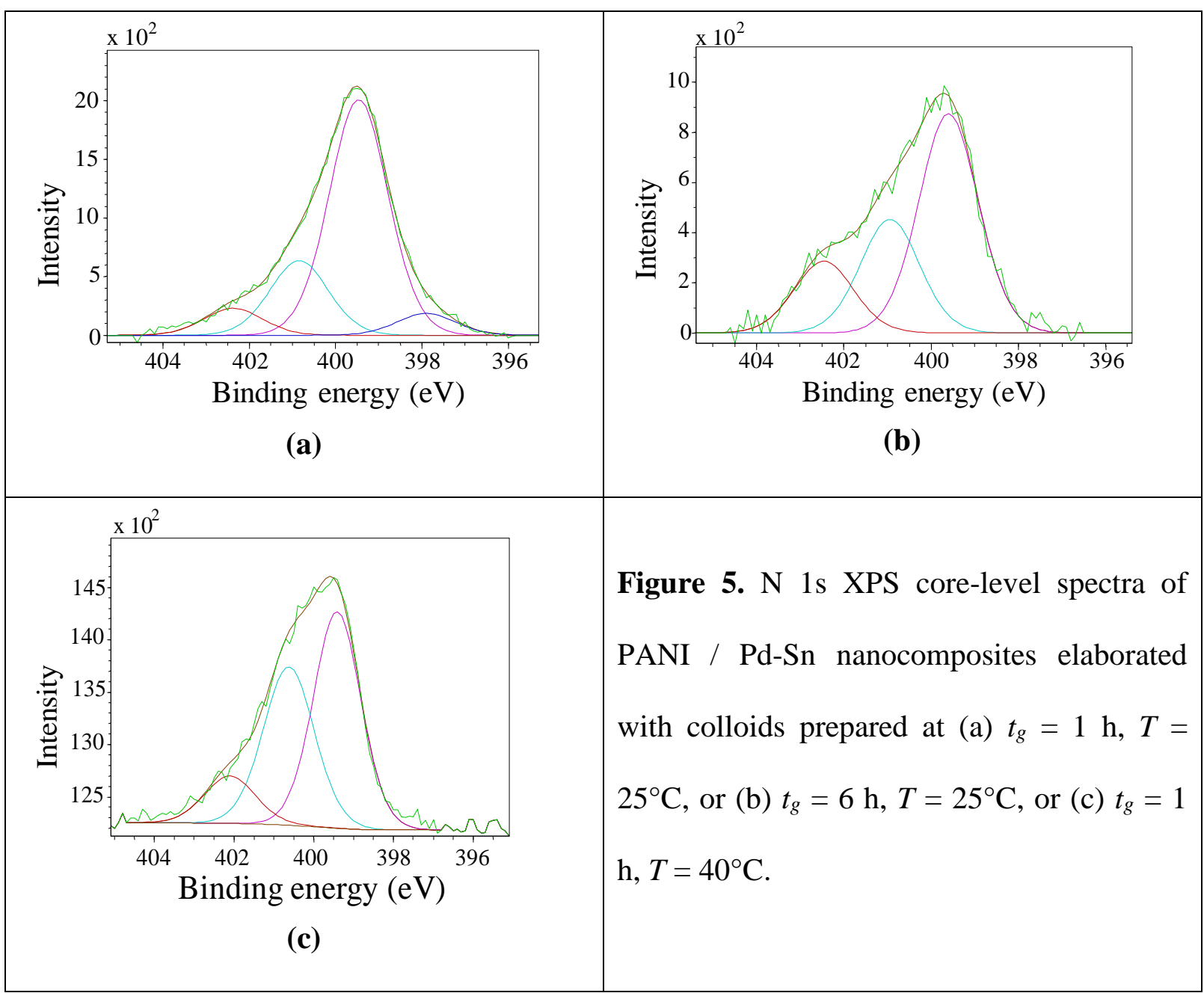

Table 3. Binding energy and percentage of each N 1s component of PANI nanostructures and PANI / Pd-Sn nanocomposites (XPS data).

\begin{tabular}{|c|c|c|c|c|c|c|c|c|c|c|c|}
\hline & \multicolumn{2}{|c|}{$-\mathrm{N}=$} & \multicolumn{2}{|c|}{$-\mathrm{NH}-$} & \multicolumn{5}{|c|}{$-\stackrel{+*}{\mathrm{NH}}-$ and $-\stackrel{+}{\mathrm{NH}}=$} & \multirow[b]{2}{*}{$\mathrm{N}^{+} / \mathrm{N}=$} & \multirow[b]{2}{*}{$\mathrm{N}^{+} / \mathrm{NH}$} \\
\hline & $\begin{array}{c}\text { Position } \\
(\mathrm{eV})\end{array}$ & $\%$ & $\begin{array}{c}\text { Position } \\
(\mathrm{eV})\end{array}$ & $\%$ & $\begin{array}{c}\text { Position } \\
\text { (eV) }\end{array}$ & $\%$ & $\begin{array}{c}\text { Position } \\
(\mathrm{eV})\end{array}$ & $\%$ & $\begin{array}{c}\text { Total } \\
(\%)\end{array}$ & & \\
\hline $\begin{array}{c}\text { PANI } \\
\text { nanostructure }\end{array}$ & 397.9 & 14.2 & 399.2 & 58.7 & 400.7 & 20 & 402.3 & 7.2 & 27.2 & 1.9 & 0.5 \\
\hline
\end{tabular}




\begin{tabular}{|c|c|c|c|c|c|c|c|c|c|c|c|}
\hline $\begin{array}{c}\text { PANI/Pd-Sn } \\
\text { nanocomposite } \\
\text { Solution A }\end{array}$ & 397.9 & 6.1 & 399.5 & 65.7 & 400.9 & 20.7 & 402.4 & 7.6 & 28.3 & 4.6 & 0.4 \\
\hline $\begin{array}{c}\text { PANI/Pd-Sn } \\
\text { nanocomposite } \\
\text { Solution B }\end{array}$ & - & - & 399.6 & 54.2 & 401 & 28.1 & 402.5 & 17.8 & 45.9 & - & 0.85 \\
\hline $\begin{array}{c}\text { PANI/Pd-Sn } \\
\text { nanocomposite } \\
\text { Solution C }\end{array}$ & - & - & 399.4 & 49.5 & 400.6 & 39 & 402.1 & 11.6 & 50.7 & - & 1.02 \\
\hline
\end{tabular}

After $e x$-situ addition of colloids, the amount of imine groups decreases for solution A and goes to zero for solutions B and C. With these latter, the amount of amines decreases also. In the same time, the doping level rises, especially with the two last solutions where the doping occurs on both imine and amine groups. These results prove that palladium and Sn act as dopants by oxidation of the amines to give $-\stackrel{+*}{\mathrm{NH}}-$ and protonation of the imines leading to $-\stackrel{+}{N}^{H}=$. The protonation can occur thanks to the molecules of the anionic complexes: $\mathrm{H}_{2} \mathrm{PdCl}_{4}$ or $\mathrm{HPdCl}_{3}\left(\mathrm{H}_{2} \mathrm{O}\right)[13-16,19]$. The doping by protonation is then not only due to $\mathrm{HCl}$ but can also be induced by the anionic complexes of Pd.

It seems that the doping occurs preferentially on the imine groups and then continues on the amine sites when imines groups are completely depleted.

Concerning the morphological structure of the nanocomposites, no change is observed compared to PANI nanostructures.

\subsection{Mechanism of interaction of colloidal particles with PANI nanostructures}


In order to understand the mechanism of interaction between the colloids and PANI chains, the nanocomposites elaborated by the in-situ and ex-situ methods are analyzed by UV-Vis spectroscopy (Figure 6).

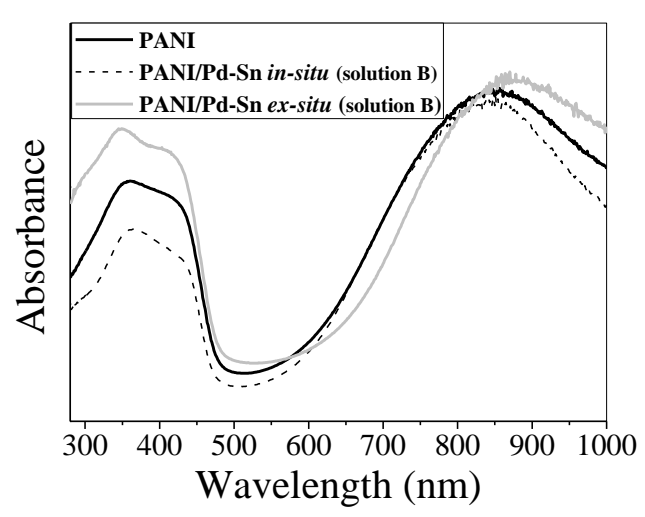

(a)

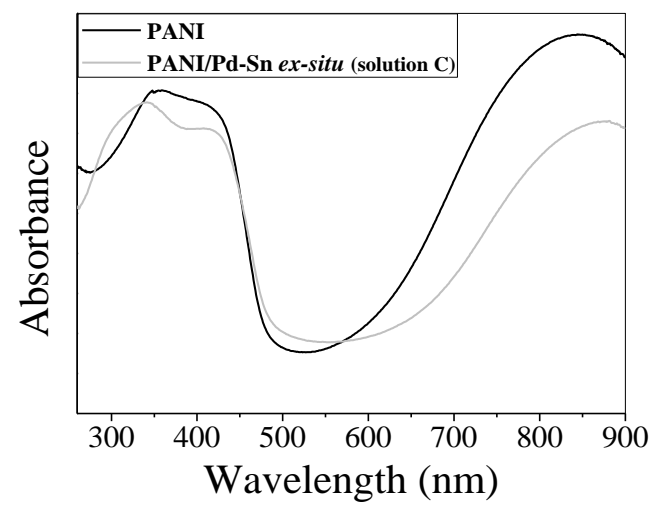

(b)

Figure 6. UV-Vis spectra of (a) PANI nanostructures, in-situ and ex-situ PANI/Pd-Sn nanocomposites prepared at $t_{g}=6 \mathrm{~h}$ and $T=25^{\circ} \mathrm{C}$, and (b) PANI nanostructures and ex-situ PANI/Pd-Sn nanocomposite prepared at $t_{g}=1 \mathrm{~h}$ and $T=40^{\circ} \mathrm{C}$.

Polyaniline doped with $\mathrm{HCl}$ is characterized by three absorption bands. The one at $360 \mathrm{~nm}$ is attributed to the benzene ring system; the two other ones at 420 and $850 \mathrm{~nm}$ are assigned to polaron- $\pi^{*}$ and $\pi$-polaron transitions respectively [21,29-32].

The presence of ex-situ deposited colloids on PANI leads to a shift of the $\pi$ - $\pi^{*}$ transition to a lower wavelength with an increase in its intensity. This shift indicates a possible interaction between ionic palladium and nitrogen atoms by protonation, oxidation or complexation. The increase in intensity shows the presence of metallic Pd. These spectra present also a shift of the $\pi$-polaron transition to a higher wavelength and a small shoulder centered at $300 \mathrm{~nm}$. The red shift of the $\pi$-polaron transition to around $870 \mathrm{~nm}$ may be due to the increase of the degree 
of delocalization of charge carriers, thus increasing the doping level. The presence of the shoulder at about $300 \mathrm{~nm}$ indicates the presence of palladium anionic complexes.

In the case of in-situ addition of colloids, no significant change in the UV-Vis spectrum is observed compared to the PANI nanostructures. The in-situ addition of the colloids does not seem to affect the doping level.

Figure 7 shows the Pd 3d and Sn 3d core-level XPS spectra of the PANI nanostructures exsitu treated with colloids.

(b)



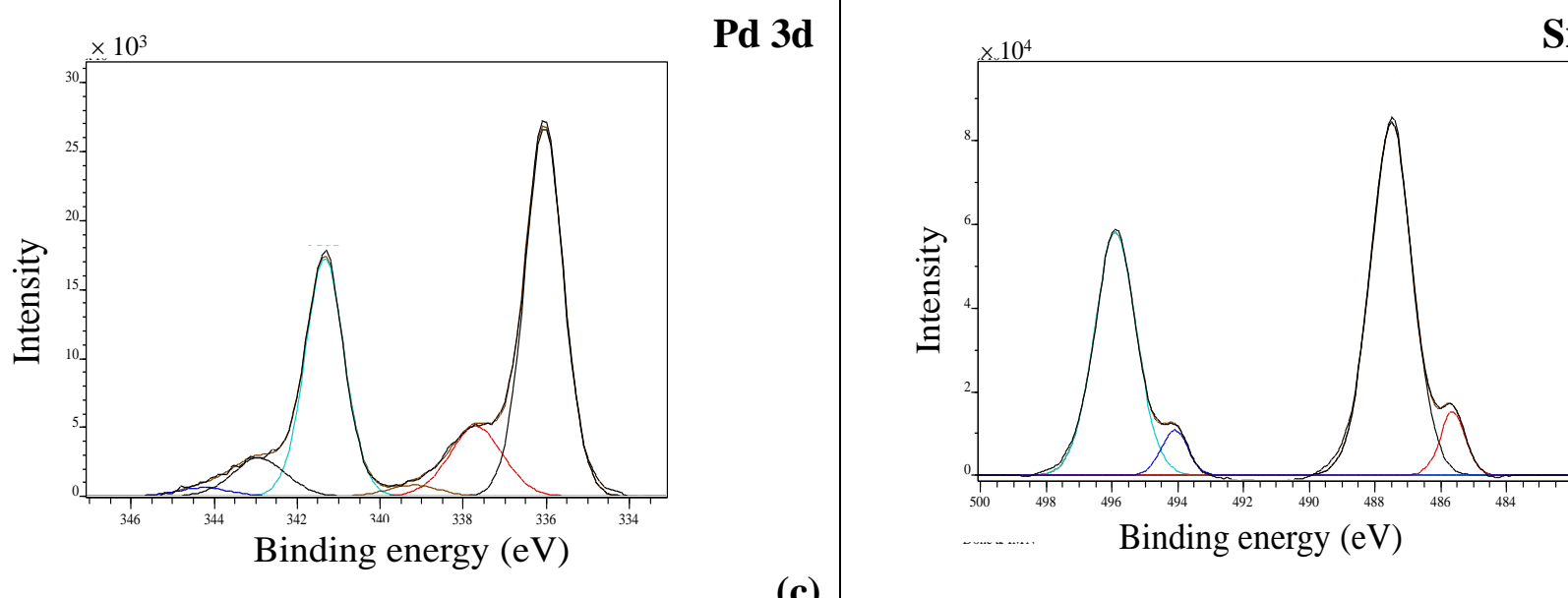

Binding energy $(\mathrm{eV})$

(c)

(c)

Figure 7. Pd 3d and Sn 3d core-level XPS spectra of PANI/Pd-Sn nanocomposites ex-situ prepared with (a) solution A, (b) solution B and (c) solution C.

Each of the Pd and Sn spectra presents a doublet corresponding to $3 d_{5 / 2}$ and $3 d_{3 / 2}$ with a binding energy difference of about $5.3 \mathrm{eV}$ for $\mathrm{Pd} 3 \mathrm{~d}$ and $8.5 \mathrm{eV}$ for $\mathrm{Sn} 3 \mathrm{~d}$ [33].

Each Pd spectrum ((a), (b) and (c)) can be fitted with three spin-orbit-split doublets. The doublet with the $\mathrm{Pd} 3 \mathrm{~d}_{5 / 2}$ peak lying at around $336 \mathrm{eV}$ is attributed to $\mathrm{Pd}(0)$, the one at around $337 \mathrm{eV}$ is assigned to $\mathrm{Pd}(\mathrm{II})[20,33,34]$ and the last one at about $338.5 \mathrm{eV}$ is due to the formation of coordination bonds between palladium ions and chlorine atoms to form the anionic complexes [33] but also with nitrogen atoms of the polymer chain [13,35]. Indeed, the complexation of silver and copper ions with PANI has also been reported to form PANI- $\mathrm{Ag}^{+}$ [36] and PANI-Cu ${ }^{2+}[37]$ systems.

The composites containing colloids prepared at $t_{g}=1 \mathrm{~h}$ and $T=25^{\circ} \mathrm{C}$ present a low level of doping since the quantity of adsorbed colloids is low (Cf. Figure 4, \% of Pd and $\mathrm{Sn}$ ).

The Sn 3d5/2 spectra (a) and (b) can be decomposed only into one peak at about $487 \mathrm{eV}$ assigned to its ionic states, $\mathrm{Sn}^{4+}$ as a result of the reduction of $\mathrm{Pd}^{2+}$ to its metallic state, and $\mathrm{Sn}^{2+}$ coming from the $\mathrm{SnCl}_{2}$ salt dissolved in $\mathrm{HCl}$, and used in excess in the stabilization step 
of colloids. The Sn 3d5/2 spectrum (c) presents an additional component at $485.5 \mathrm{eV}$ attributed to metallic tin $\operatorname{Sn}(0)$.

Concerning the in-situ addition of colloids (Figure 8), all Pd and Sn XPS spectra of composites (except Figure 8c), show three components: a metallic one, an ionic one and a coordination one. The Sn coordination component can be explained by the complexation reactions either between PANI and $\mathrm{SnCl}_{4}$, known as a Lewis acid [38], or between $\mathrm{Sn}^{2+}$ and chlorine atoms to form $\mathrm{SnCl}_{3}{ }^{-}$ions.

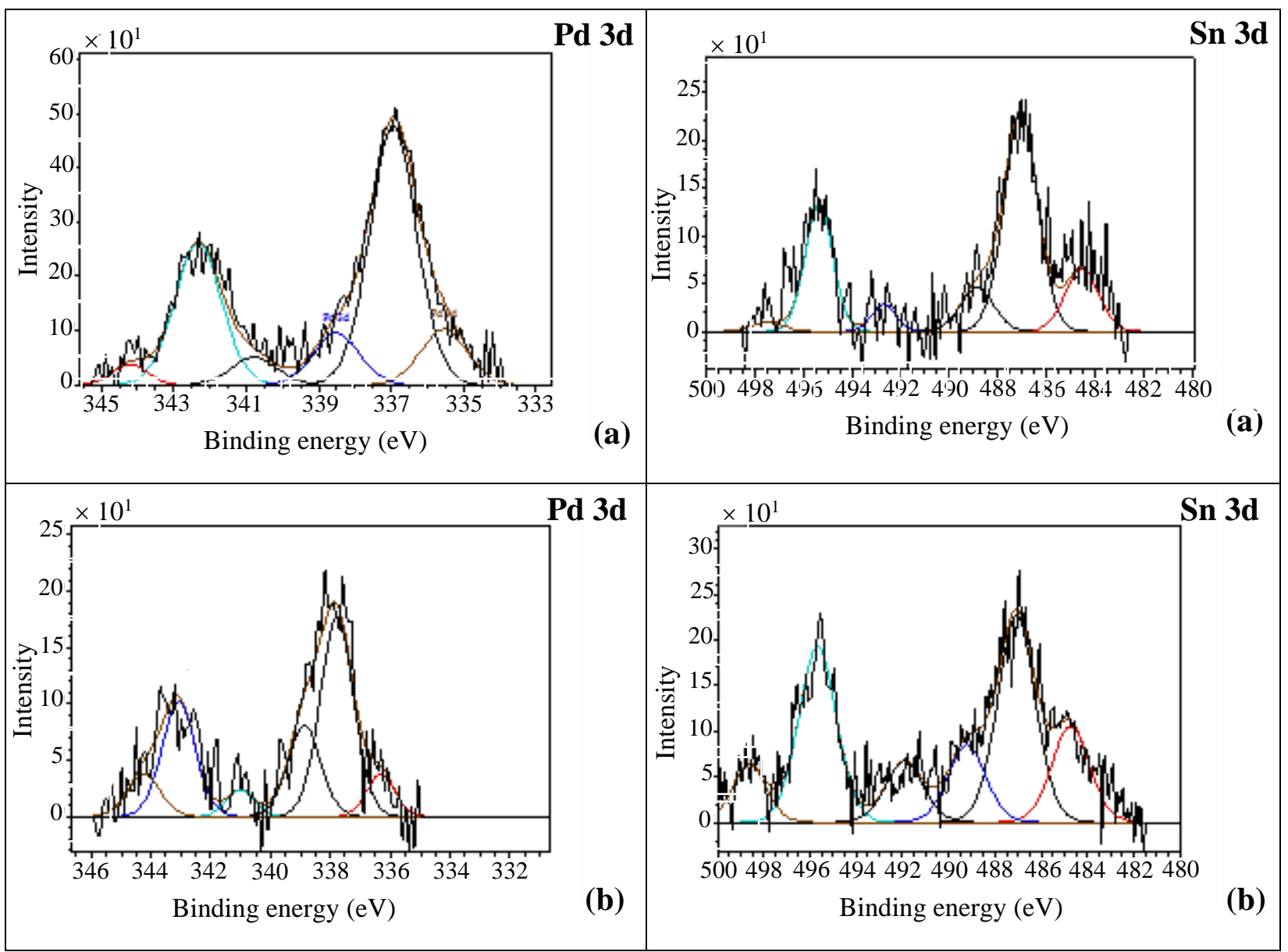




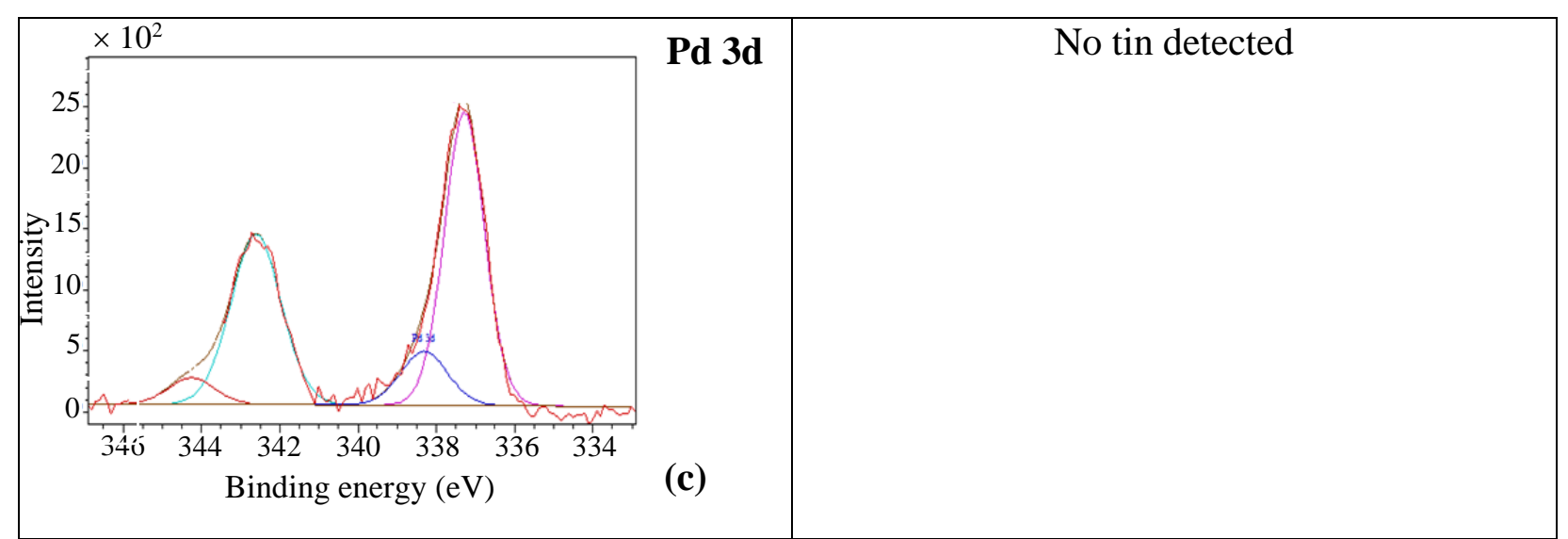

Figure 8. Pd 3d and Sn 3d core-level XPS spectra of PANI/Pd-Sn nanocomposites in-situ prepared with (a) solution A, (b) solution B and (c) solution C.

This study has thus shown the participation of colloids in the doping process. In the following, we propose different doping mechanisms of PANI/colloids nanocomposites elaborated either by the in-situ or by the ex-situ method.

1. Acidic doping with Brönsted acids by protonation of the imines with $\mathrm{HCl}, \mathrm{H}_{2} \mathrm{PdCl}_{4}$, $\mathrm{HPdCl}_{3}\left(\mathrm{H}_{2} \mathrm{O}\right)$ or $\mathrm{HSnCl}_{3}$ according to the following mechanisms:
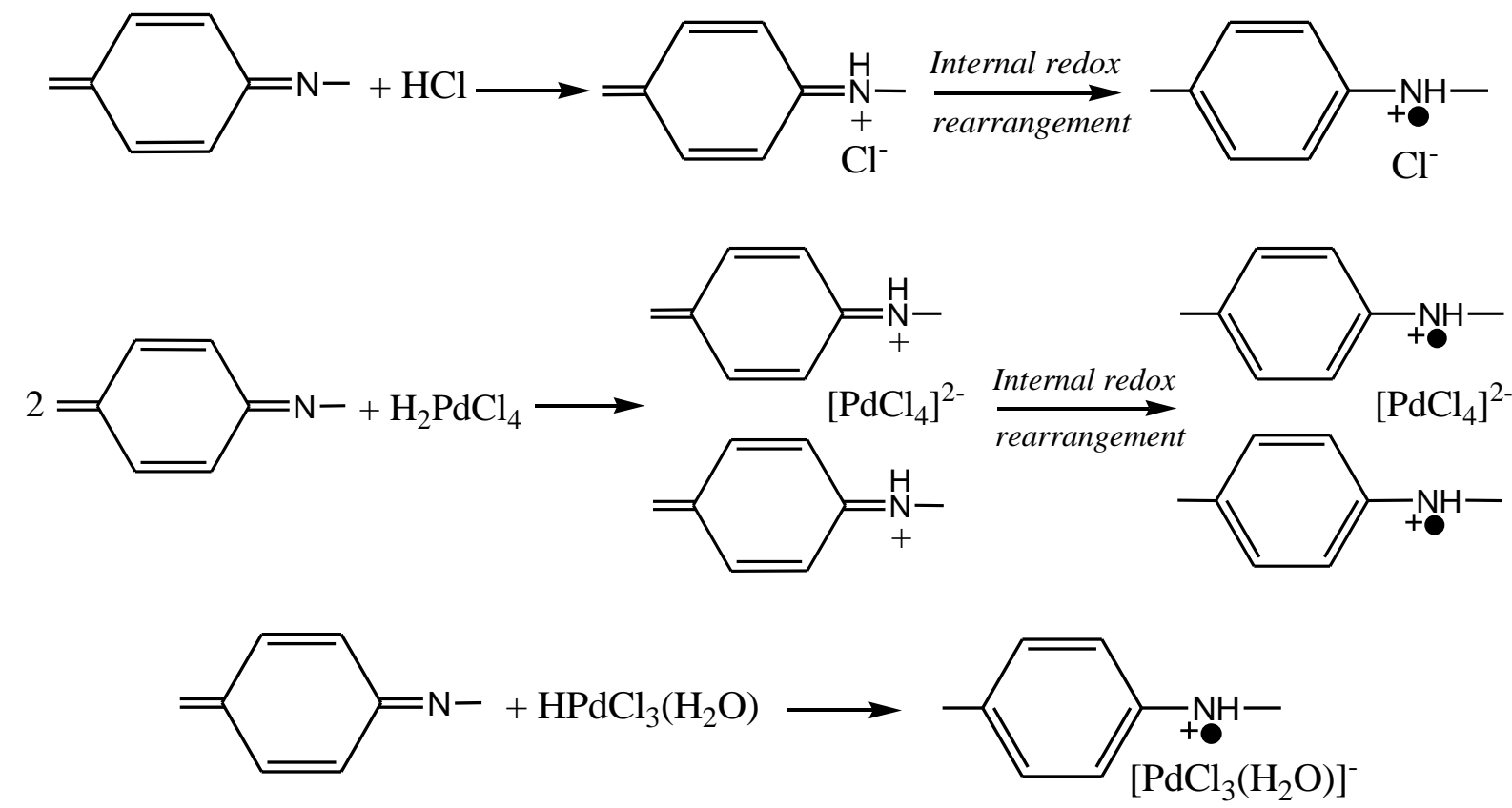


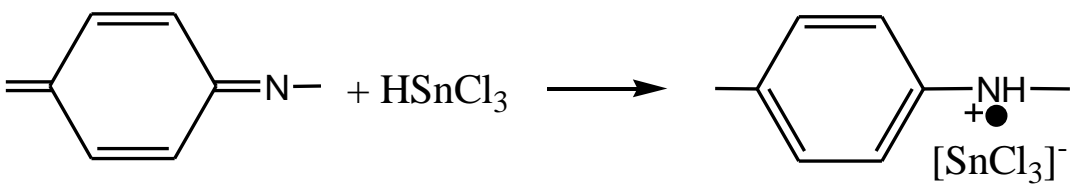

2. Doping by oxidation of the amines with $\mathrm{Pd}$ ions $\left(\mathrm{Pd}^{2+}\right)$ or $\mathrm{Sn}$ ions $\left(\mathrm{Sn}^{2+}\right.$ and $\left.\mathrm{Sn}^{4+}\right)$ :

The doping with $\mathrm{Pd}^{2+}$ is favoured since the difference in standard potentials between PANI $\left(\mathrm{E}^{0}(-\stackrel{+\bullet}{\mathrm{NH}}-/-\mathrm{NH}-)<-1 \mathrm{~V}[39]\right)$ and palladium $\left(\mathrm{E}^{0}\left(\mathrm{Pd}^{2+} / \mathrm{Pd}\right)=0.99 \mathrm{~V}\right)$ is higher than that with $\operatorname{tin}\left(\mathrm{E}^{0}\left(\mathrm{Sn}^{4+} / \mathrm{Sn}^{2+}\right)=0.14 \mathrm{~V}\right.$ and $\left.\mathrm{E}^{0}\left(\mathrm{Sn}^{2+} / \mathrm{Sn}\right)=-0.14 \mathrm{~V}\right)$

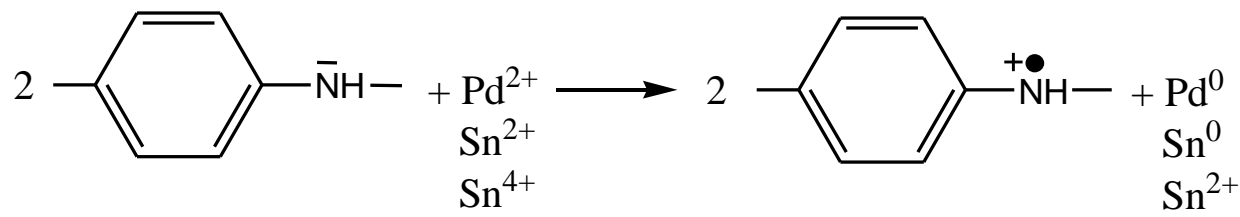

3. Imines acidic doping with Lewis acids $\left(\mathrm{SnCl}_{4}\right.$ and $\left.\mathrm{PdCl}_{2}\right)$ to form acid-base complexes:

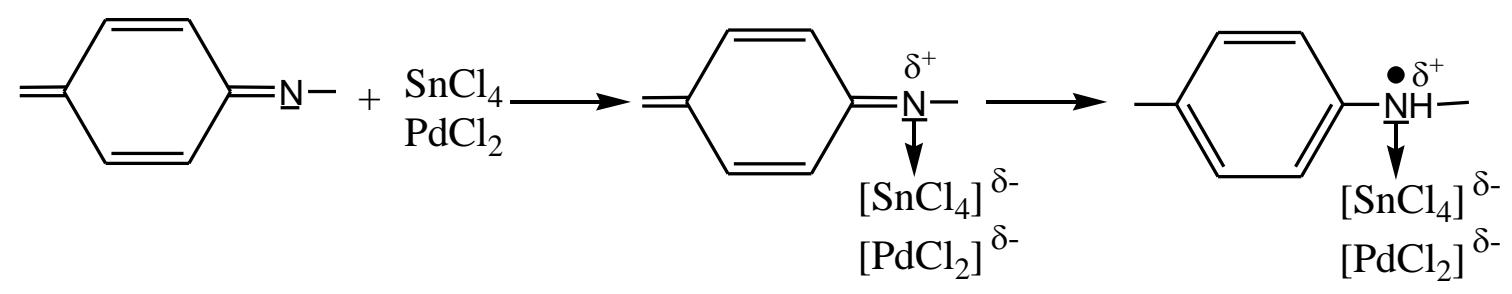

4. Amines acidic doping with Lewis acids $\left(\mathrm{SnCl}_{4}\right.$ and $\left.\mathrm{PdCl}_{2}\right)$ to form acid-base complexes:

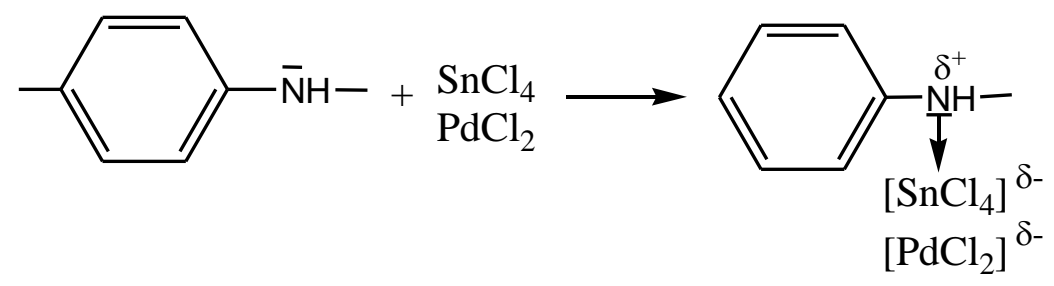


It has also been shown in the literature that polyaniline could be transformed to its conductive form using Lewis acids as dopants such as $\mathrm{SnCl}_{4}$ [38] or $\mathrm{BF}_{3}$ [40].

\section{Conclusion}

This work described a novel route to elaborate polymer / metal nanocomposites. The metallic nanoparticles have been introduced in the matrix from a $\mathrm{Pd} / \mathrm{Sn}$ colloidal solution via two ways: the in-situ one where the monomer and the colloids are mixed and the ex-situ one where the colloids are added after polymerization.

The in-situ addition of colloids affects mainly the morphology of the nanocomposites with a rise of the surface area compared to PANI nanostructures. Concerning the ex-situ method, it influences the doping level of the polymer leading to a higher quantity of positively charged nitrogen. We proposed different doping mechanisms involving the protonation, the oxidation and the complexation of imine and amine groups by palladium and tin salts and complexes. This increase in the doping level is not observed with the in-situ method certainly due to the lower quantity of colloids introduced in the nanocomposites as proved by XPS analyses. The morphology of PANI nanostructures seems to remain unmodified after the ex-situ addition of colloids.

The amount of colloids adsorbed on the surface of PANI thin films, depends greatly on the elaboration conditions of the colloidal solutions.

\section{Conflict of Interest}

The authors declare that they have no conflict of interest.

\section{References}


[1] Z. Peng, L. Guo, Z. Zhang, B. Tesche, T. Wilke, D. Ogermann, S. Hu, K. Kleinermanns, Micelle-assisted one-pot synthesis of water-soluble polyaniline-gold composite particles, Langmuir 22 (2006) 10915-10918.

[2] Y. Xian, Y. Hu, F. Liu, Y. Xian, H. Wang, L. Jin, Glucose biosensor based on Au nanoparticles-conductive polyaniline nanocomposite, Biosens. Bioelectron. 21 (2006) 1996-2000.

[3] A. Athawale, S.V. Bhagwat, P.P. Katre, Nanocomposite Pd-polyaniline as a selective methanol sensor, Sensor. Actuat. B-Chem. 114 (2006) 263-267.

[4] R.J. Tseng, J. Huang, J. Ouyang, R.B. Kaner, Y. Yang, Polyaniline nanofiber/gold nanoparticle nonvolatile memory, Nano. Lett. 5 (2005) 1077-1080

[5] M.A. Malik, M.T. Galkowski, H. Bala, B. Grzybowska, P.J. Kulesza, Evaluation of polyaniline films containing traces of dispersed platinum for protection of stainless steel against corrosion, Electrochim. Acta 44 (1999) 2157-2163.

[6] C.C. Hu, E. Chen, J.Y. Lin, Capacitive and textural characteristics of polyanilineplatinum composite films, Electrochim. Acta 47 (2002) 2741-2749.

[7] T. Amaya, D. Saio, T. Hirao, Template synthesis of polyaniline/Pd nanoparticle and its catalytic application, Tetrahedron Lett. 48 (2007) 2729-2732.

[8] D. N. Muraviev, J. Macanàs, M. Farre, M. Munoz, S. Alegret, Novel routes for intermatrix synthesis and characterization of polymer stabilized metal nanoparticles for molecular recognition devices, Sensor. Actuat. B-Chem. 118 (2006) 408-417.

[9] L. Torsi, M. Pezzuto, P. Siciliano, R. Rella, L. Sabatini, L. Valli, P.G. Zambonin, Conducting polymers doped with metallic inclusions: New materials for gas sensors, Sensor. Actuat. B-Chem. 48 (1998) 362-367. 
[10] M.E. Inoue, K.W. Nebesny, Q. Fernando, M.M. Castillo-Ortega, M. Inoue, Complexation of electroconducting polypyrrole with copper, Synth. Met. 38 (1990) 205-212.

[11] A.A. Athawale, S.V. Bhagwat, P.P. Katre, A.J. Chandwadkar, P. Karandikar, Aniline as a stabilizer for metal nanoparticles, Mater. Lett. 57 (2003) 3889-3894.

[12] J. G. Wang, K. G. Neoh, E. T. Kang, Preparation of nanosized metallic particles in polyaniline, J. Colloid Interface Sci. 239 (2001) 78-86.

[13] A. Drelinkiewicz, M. Hasik, M. Choczynski, Preparation and properties of polyaniline containing palladium, Mater. Res. Bull. 33(5) (1998) 739-762.

[14] A. Drelinkiewicz, M. Hasik, S. Quillard, C. Paluszkiewicz, Infrared and Raman studies of palladium-nitrogen-containing polymers interactions, J. Mol. Struct. 511-512 (1999) $205-215$.

[15] M. Hasik, A. Drelinkiewicz, E. Wenda, C. Paluszkiewicz, S. Quillard, FTIR spectroscopic investigations of polyaniline derivatives-palladium systems, J. Mol. Struct. 596 (2001) 89-99.

[16] W. Dhaoui, M. Hasik, D. Djurado, A. Bernasik, A. Pron, Redox behaviour of polyaniline-palladium catalytic system in the presence of formic acid, Synth. Met. 160 (2010) 2546-2551.

[17] O.P. Dimitriev, Doping of polyaniline by transition-metal salts, Macromolecules 37 (2004) 3388-3395.

[18] O.P. Dimitriev, Interaction of polyaniline and transition metal salts: formation of macromolecular complexes, Polym. Bull. 50 (2003) 83-90.

[19] M. Hasik, E. Wenda, A. Bernasik, K. Kowalski, J.W. Sobczak, E. Sobczak, E. Bielanska, Poly(o-toluidine) as the matrix for incorporation of palladium species from $\mathrm{PdCl}_{2}$ aqueous solutions, Polymer 44(2003) 7809-7819. 
[20] D. Nicolas-Debarnot, M. Pascu, C. Vasile, F. P-Epaillard, Influence of the polymer pretreatment before its electroless metallization, Surf. Coat. Tech. 200 (2006) 4257-4265.

[21] H. Kebiche, D. Debarnot, A. Merzouki, F. Poncin-Epaillard, N. Haddaoui, Relationship between ammonia sensing properties of polyaniline nanostructures and their deposition and synthesis methods, Anal. Chim. Acta 737 (2012) 64-71.

[22] L. Rasmusen, Chr.K. Jorgensen, Palladium (II) complexes: spectra and formation constants of ammonia and ethylènediamine complexes, Acta Chem. Scand. 22 (1968) 2313-2323.

[23] F. Bozon-Verduras, A. Omar, J. Escard, and B. Pontvianne, Chemical state and reactivity of supported palladium: I. Characterization by XPS and UV-visible spectroscopy, J. Catal. 53 (1978) 126-134.

[24] G.R. Tauszik, A. Marzi, and R. Covini, Electronic reflectance spectra of palladium-onalumina catalysts, React. Kinet. Catal. Lett. 7 (1977) 7-14.

[25] A.V. Gaikwad, G. Rothenberg, In-situ UV-visible study of Pd nanocluster formation in solution, Phys. Chem. Chem. Phys. 8 (2006) 3669-3675.

[26] S. Golczak, A. Kanciurzewska, M. Fahlman, K. Langer, J.J. Langer, Comparative XPS surface study of polyaniline thin films, Solid State Ionics 179 (2008) 2234-2239.

[27] B. Sreedhar, M. Sairam, D.K. Chattopadhyay, P.P. Mitra, D.V. Mohan Rao, Thermal and XPS studies on polyaniline salts prepared by inverted emulsion polymerization, J. Appl. Polym. Sci. 101 (2006) 499-508.

[28] P. Xu, X. Han, B. Zhang, Y. Du, H.L. Wang, Multifunctional polymer-metal nanocomposites via direct chemical reduction by conjugated polymers. Chem. Soc. Rev. 43 (2014) 1349-1360. 
[29] Y. Xia, J.M. Wiesinger, A.G. MacDiarmid, Camphorsulfonic acid fully doped polyaniline emeraldine salt: conformations in different solvents studied by an ultraviolet/visible/near-infrared spectroscopic method, Chem. Mater. 7 (1995) 443-445.

[30] X. Li, X. Li, G. Wang, Fibrillar polyaniline/diatomite composite synthesized by onestep in situ polymerisation method, Appl. Surf. Sci. 249 (2005) 266-270.

[31] P.L.B. Araujo, E.S. Araujo, R.F.S. Santos, A.P.L. Pacheco, Synthesis and morphological characterization of PMMA/Polyaniline nanofiber composites, Microelectr. J. 36 (2005) 1055-1057.

[32] S.E. Moulton, P.C. Innis, L.A.P. Kane-Maguire, O. Ngamna, G.G. Wallace, Polymerisation and characterisation of conducting polyaniline nanoparticle dispersions, Curr. Appl. Phys. 4 (2004) 402-406.

[33] J.F. Moulder, W.F. Stickle, P.E. Sobot, K.D. Bomben, Handbook of X-ray Photoelectron Spectroscopy, Physical Electronics Inc., New York (1995).

[34] J.G. Wang, K.G. Neoh, E.T. Kang, Polyaniline-palladium composite coatings for metallization of polyethylene substrate, Appl. Surf. Sci. 218 (2003) 231-244.

[35] W.J. Dressick, C.S. Dulcey, J.H. Georger, G.S. Calabrese, J.M. Calvert, Covalent binding of $\mathrm{Pd}$ catalysts to ligating self-assembled monolayer films for selective electroless metal deposition, J. Electrochem. Soc. 141 (1994) 210-220.

[36] A.Q. Zhang, C.Q. Cui, J.Y. Lee, and F.C. Loh, J. Electrochem. Soc. 142 (1995) 1098.

[37] M. Higuchi, D. Imoda, and T. Hirao, Redox Behavior of Polyaniline-Transition Metal Complexes in Solution, Macromolecules 29(1996) 8277-8279.

[38] I. Kulszewicz-Bajer, A. Pron, J. Abramowicz, C. Jeandey, J-L Oddou, J.W. Sobczak, Lewis acid doped polyaniline: preparation and spectroscopic characterization, Chem. Mater. 11 (1999) 552-556. 
[39] A. Mansour, F. Poncin-Epaillard, D. Debarnot, Affinity and distribution of silver nanoparticles within plasma polymer matrices, J. Mater. Sci. 54 (2019)12972-12987.

[40] D. Chaudhuri, A. Kumar, I. Rudra, D. D. Sarma, Synthesis and spectroscopic characterization of highly conducting $\mathrm{BF}_{3}$-doped polyaniline, Adv. Mater. 13 (2001) $1548-1551$. 